OPEN ACCESS

Edited by:

Dongran Song,

Central South University, China

Reviewed by:

Jiawei Zhu,

Chang'an University, China

Jian Yang,

Central South University, China

Mingzhu Tang,

Changsha University of Science

and Technology, China

${ }^{*}$ Correspondence:

Tao Yu

taoyu1@scut.edu.cn

Specialty section:

This article was submitted to Smart Grids,

a section of the journal

Frontiers in Energy Research

Received: 14 March 2021 Accepted: 30 March 2021

Published: 07 May 2021

Citation:

Wang K, Li Y, Wang X, Zhao Z, Yang $N$, Yu S, Wang $Y$, Huang $Z$ and Yu T (2021) Full Life Cycle

Management of Power System Integrated With Renewable Energy:

Concepts, Developments and Perspectives.

Front. Energy Res. 9:680355. doi: 10.3389/fenrg.2021.680355

\section{Full Life Cycle Management of Power System Integrated With Renewable Energy: Concepts, Developments and Perspectives}

\author{
Kang Wang ${ }^{1}$, Yikai Li ${ }^{1}$, Xiaojun Wang ${ }^{1}$, Zengtao Zhao ${ }^{1}$, Ning Yang ${ }^{2}$, Shengcan $Y u^{2}$, \\ Yi Wang ${ }^{1}$, Zhanhong Huang ${ }^{2}$ and Tao Yu ${ }^{2 *}$
}

${ }^{1}$ CSG POWER GENERATION CO., LTD., Guangzhou, China, ${ }^{2}$ School of Electric Power Engineering, South China University of Technology, Guangzhou, China

Under high-penetration of renewable energy, power grid is facing with the development problems such as production delay, wind and solar power abandoning. With the continuous growth of renewable energy installation such as wind power, photovoltaic $(\mathrm{PV})$, as well as the increase of power generation capacity, it is urgent to increase peakload and frequency regulation capacity on a large scale to alleviate the consumption problems caused by large renewable energy integration, and then requires power generation enterprises of peak-load and frequency regulation to increase relevant equipment assets. As a result, peak-load and frequency regulation enterprises must carry out scientific cost management of equipment assets. This paper introduces the concepts, developments and perspectives of life cycle cost (LCC) management of equipment assets in high-penetrated renewable energy power grid, and probes into cost collection and estimation scheme in the process of equipment asset management.

Keywords: high-penetrated renewable energy power grid, peak-load and frequency regulation, asset full life cycle cost, cost collection and estimation, full life cycle management

\section{INTRODUCTION}

\section{Development and Consumption of New Energy}

With the continuous increase of environmental pressure and energy demand caused by energy development, the proportion of wind power, photovoltaic (PV) power generation and other renewable energy in the power grid is increasing year by year. Through policy guidance, preferential subsidies and other incentive policies, countries vigorously promote investment in wind power, PV and other renewable energy, develop advanced technology and architecture systems, so as to promote large-scale grid connection of renewable energy (Wen et al., 2008). According to statistics, by the end of 2020, the cumulative installed capacity of global offshore wind power has reached $32.5 \mathrm{GW}$, and 162 offshore wind farms have been put into operation, an increase of $19.1 \%$ over the same period at the end of 2018, which indicates the promising prospect of renewable energy power development (Hu and Cheng, 2013; Feng et al., 2015). The variation of installed capacity of offshore wind power in the past decade is shown in Figure 1.

The rapid development of renewable energy leads to major changes in the investment scale and asset management mode of power system. In 2019, the annual investment in renewable 


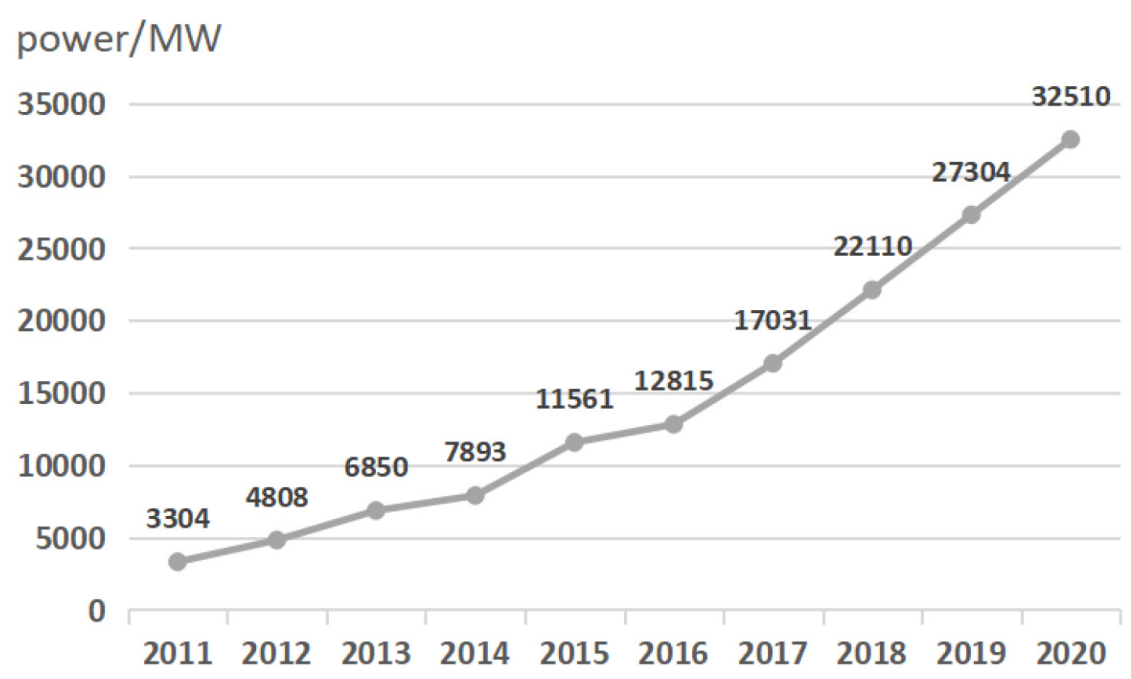

FIGURE 1 | The installed capacity of offshore wind power in the past decade.

energy power in the world reached 53.1 billion United States dollars, and the rapid growth of asset investment greatly promoted the research and development of related technologies and implementation of projects. However, in the process of rapid development of renewable energy, the problem of renewable energy accommodation, such as abandoned wind and solar, is becoming increasingly serious with the disharmony of the spatial and temporal distribution of capacity and load (Hu and Cheng, 2013).

Since 2012, China's installed PV capacity began to grow rapidly. In 2014, accommodation problem caused by this rapid growth began to appear, and the problem of abandoned solar aroused the attention of whole society. Therefore, the power grid needs to further improve the ability to absorb new energy (John, 2017). According to Information Brief of PV Power Generation Construction from January to September 2015 released by National Energy Administration, cumulative PV power generation in China from January to September was 30.60 billion $\mathrm{k} \cdot \mathrm{Wh}$, and PV power abandoning was about 3.03 billion $\mathrm{k} \cdot \mathrm{Wh}$, with a solar abandoning rate of $10 \%$. After wind power encountered wind abandoning dilemma, PV power generation also fell into the dilemma of capacity allocation redundancy (Bird et al., 2016). In the development of wind power in the past five years, two phenomena have been accompanied by: (1) the good news of the continuous increase in installed capacity of renewable energy; (2) the dilemma of "abandoned electricity" such as abandoned wind and solar due to insufficient accommodation capacity. The statistics of China's abandoned wind power from 2011 to 2015 are shown in Figure 2. From 2011 to the first half of 2015, China's total wind power on grid was 561.774 billion $\mathrm{k} \cdot \mathrm{Wh}$, the total abandoned wind power was 80.191 billion $\mathrm{k} \cdot \mathrm{Wh}$, and the average abandoned wind rate was $14.27 \%$. In addition, large-scale integration of new energy power generation has made power frequency imbalances increasingly frequent (Basmadjian and Meer, 2018). In the context of China's economy entering the new normal of medium and high-speed growth, the problem of abandoned power has become increasingly prominent (Kasis et al., 2016).

Peak-load and frequency regulation power supplies can well alleviate accommodation problems caused by large-scale grid connection of renewable energy, and Improve system operation level (Chen et al., 2009). Fujian province of China increased the average utilization hours of nuclear power by more than $700 \mathrm{~h}$ year-on-year, and without abandoned wind, water, and solar phenomenon, which improve the utilization of electric power production equipment and increase the return on investment (Kasis et al., 2016). Renewable energy power generation investment rise needs to pay attention to equipment management and investment effectiveness (Kasis et al., 2016; Dui et al., 2018). Hence, under the guidance of renewable power investment mode and system, the investment planning for renewable energy industries such as wind power and PV and the asset management of power enterprises should take into account the economy and reliability in full life cycle, so that the huge renewable energy power construction can get a better return on investment (Yildiz and Kazimi, 2006; Spertino and Graditi, 2014). Combined with power equipment management and related technical characteristics in large-scale renewable energy grid connection, this paper explores a refined, multiangle and strongly related asset cost management mode, which provides an important method channel for the environmental friendliness and green economic function of renewable energy power (Billinton and Huang, 2010; Dui et al., 2018).

\section{Organization of the Paper}

The rest of this article is arranged as follows: Section "Power Assets Full Life Cycle Cost Management" summarizes the development process and research status of the whole life cycle cost management of assets and power equipment at home and abroad. Section "LCC Cost Estimation Model" gives the estimation model of power equipment LCC by introducing the structure and estimation method of LCC in detail. Section 


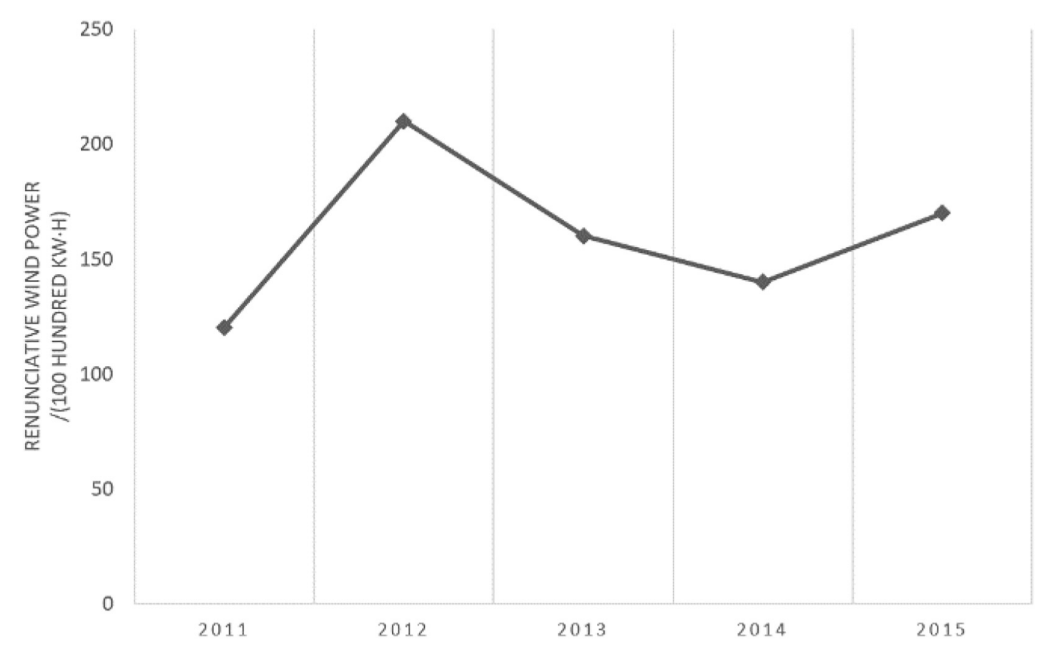

FIGURE 2 | The statistics on abandoned wind power nationwide between 2011 and 2015.

"Conclusion" summarizes the full text and gives the direction of the next stage of research.

\section{POWER ASSETS FULL LIFE CYCLE COST MANAGEMENT}

\section{Asset Life-Cycle Cost Management}

According to IEC60300-3-3 standard formulated by International Electrotechnical Commission, full life cycle refers to the life cycle stage of equipment, which can be divided into concept and definition stage (Hedley-Whyte, 2000), design and development stage (Arif and Khan, 2010), manufacturing stage (Lee et al., 2016), installation stage (Asiedu and Gu, 1998), operation and maintenance stage (Solomon et al., 2000), and decommissioning disposal stage. Therefore, full life cycle cost (LCC) is the sum of all costs incurred in the above stages. Full LCC occurs in different property rights, which can be seen from the perspective of society (Ozbay et al., 2004), producers and users (Kiritsis et al., 1999; Mascitelli, 2004). From the perspective of asset users, most of the research focuses on the estimation and modeling of product design phase (Park and Simpson, 2003; Liu et al., 2008).

The concept of LCC originated in the United States in 1927 and was proposed by Department of defense (White, 1976; Bajaj et al., 2004). In 1933, the general audit office of the United States formally proposed the concept of LCC for the first time (White, 1976). In the 1960s, this concept was successfully applied to F16 fighters (Yeung et al., 2013). In 1996, the United States Department of defense began to formally study LCC theory, which was first used in the army. Later, Britain, France, Germany and other countries gradually applied LCC theory in the army. With the successful application of LCC theory in the military neighborhood, it gradually gained attention in the civil field (Zhang and Wang, 2012). With the gradual expansion of the application field of the theory, scholars began to focus on engineering design, equipment selection, equipment maintenance, equipment decommissioning and other aspects of extensive and in-depth research.

Literature (Asiedu and $\mathrm{Gu}, 1998$ ) described the complete steps of LCC theory and gives its reason, content and corresponding model of each step. Literature (Curry, 1989) summarized the life estimation of aerospace electronic equipment by the United States air force using LCC theory, and introduces a standardized evaluation procedure 'STEP.' Moreover, LCC technology is applied to the modernization of aircraft in-flight refueling and electronic system (Woodward, 1997; Seo et al., 2002). In literature (Furch, 2016), LCC theory is applied to establish the railway vehicle model, and the cost calculation formula of each stage is given. Besides, a prediction method for full life cycle scrap time of electronic components is established, a series of quantitative market or technical attributes were identified and obtained, and the scrap time of components was calculated by statistical method (Solomon et al., 2000). In addition, LCC analysis is carried out for the components of energy meter and resonant circuit in power system (Meyer and De Doncker, 2006; Cai et al., 2011). Literature (Nilsson and Bertling, 2007; Tian et al., 2011; Shafiee et al., 2016) applied LCC theory to wind power industry, and literature (Tian et al., 2011) established condition monitoring systems (CMS) based on LCC, which can reduce indirect damage in case of failure and provide favorable conditions for maintenance plans. Furthermore, it presents a LCC analysis strategy and employs CMS to improve the single wind turbine maintenance plan for onshore and offshore wind farms (Nilsson and Bertling, 2007). In literature (Shafiee et al., 2016), a wind farm investment cost regression model based on commodity price and seawater depth is proposed to estimate the accurate LCC.

In the fierce global competition environment, world-famous electric power enterprises have realized the importance of asset management for enterprise development, as well as electric power industry is also constantly exploring the full life cycle management and application of assets (Shahidehpour and Ferrero, 2005), so as to promote the maximum efficiency of 
assets and serve the development of enterprises. Particularly, LCC theory has been gradually promoted and applied in the electric power industry.

National Grid Corporation of United Kingdom has integrated some intelligent management tools into daily management, established a complete set of asset management information sharing platform, among which project management, production operations, maintenance, and other fields are associated, finally achieve data integration, according to the need to generate various reports for reference of all kinds of managers.

In the late 1990s, Canada's Hydro One introduced the concept of asset full life cycle management and established a complete set of asset evaluation methods (Danish et al., 2014). In addition, it is worth noting that this company's asset management business has selected professional outsourcers to be responsible for the management of some assets, which not only saves the management workload of the main business personnel, but also improves the asset management level.

Ashburton Power Company of New Zealand makes a specific asset plan before making a clear investment objective, comprehensively considering all aspects of power grid planning, equipment transformation, maintenance and so on. Secondly, based on equipment condition and load forecast, the investment plan is optimized and analyzed. Finally, the information system is adopted to analyze how to achieve the optimal unit cost in the whole process of asset procurement, construction, operation and maintenance, transportation and scrapping.

Given the current situation of the power sector in Afghanistan, for improving the electricity environment in rural and remote areas, LCC theory is introduced to establish a cost-effective hybrid system. In 2004, International Power System Conference advocated that equipment manufacturers provide management reports for full life cycle of equipment and products (Lombardi, 2003; Joseph et al., 2018). As a result, world's major electrical equipment manufacturers, such as ABB Group and Siemens, began to study full life cycle management of their products (Zhang and Cai, 2014; Zakeri and Syri, 2015). In 2005, representatives of more than 50 countries and regions, including the United Kingdom and Norway, established international organizations of asset LCC (Steen, 2005).

The asset management of international advanced electric power enterprises is aimed at minimizing the life cost of assets and maximizing the investment value: (1) pay attention to the analysis of investment in the early stage and determine the investment strategy through the optimal rating; (2) determine the health condition of the assets by rating them and determine their disposal methods to achieve the highest utilization rate; (3) the employ of information means to achieve assets procurement, construction, operation and maintenance, return and scrap of full life cycle management.

\section{Overview of Power Equipment Life Cycle Management}

In literature (Shi et al., 2009), taking a $220 \mathrm{kV}$ heavy load substation as an example, considering the loss of social output value, the comprehensive economy of full life cycle of substation construction is calculated and compared, which concludes that the scheme has the best reliability and economy is obtained.

Literature (Kim et al., 2010) establishes a two-dimensional model of power system LCC for the drawback that the application of power system LCC is traditionally limited to specific equipment or stage, in which research status of LCC technology is reviewed. The cost breakdown structure is described in detail from the device level and the system level. Besides, the maintenance cost of the combination of reliability-centered maintenance (RCM) and fault repair (overhaul) is also analyzed. On this basis, some studies have also proposed a component-costtime 3D model (Luo et al., 2011).

Literature (Cai et al., 2011) analyzed the latest progress in LCC technology, problems that should be paid attention to and several suggestions for the management of LCC. A full LCC-benefit model for energy-saving transformation of distribution network is established in literature (Karamouz et al., 2017), in which a decision method considering financial and technical constraints is proposed. It is effective to apply the model and method to the actual distribution network transformation. Besides, in order to overcome the problem of neglecting the medium and long-term cost and underestimating the short-term investment in the current economic evaluation of power system, a threedimensional LCC model of the whole power system is established from the perspective of component dimension, cost dimension and time dimension. Through the analysis of the structure of the device layer, a series of economic evaluation strategies based on LCC are proposed, and the transformation of devices with different lifetime is studied Change the cycle (Liu et al., 2012).

At present, the practice of asset LCC management mainly focuses on the following two forms:

The first is to seek a new breakthrough in asset management mode based on the cost management of full life cycle of assets. It mainly standardizes asset management through management means such as internal rules and regulations or norms of enterprises, and integrates cost management concepts into daily management, such as optimizing design schemes, equipment selection, cost schemes and other efforts to achieve the goal of the lowest asset cost of equipment or system.

Second, relying on the information system to achieve asset life cycle cost management. The labor of asset management is huge, which makes it cumbersome, time-consuming and prone to human errors. The establishment of a new information platform can break the departmental barriers, connect the processes of asset planning, design, construction, operation and maintenance, return and scrap, so that realize the cooperation of each module. The full life cycle management of assets is realized. Through the strict management of the full life cycle cost of equipment, the links of material procurement, equipment collection, financial settlement and payment are strictly controlled. The original mode of extensive management and information isolation is changed, and the equipment asset management information system of real-time dynamic and fine management is established. However, due to equipment defect state maintenance, risk assessment lacks support, which cannot provide decision-making basis for equipment overhaul and technical reform. At the same time, because of lack of effective assessment and assessment 
means, as well as lack of quantitative assessment indicators for equipment and management, resulting in most of the current power enterprises still cannot solve the contradiction between low cost and high utilization of assets.

Asset management is no longer the management of a certain link, but the management of full life cycle of the equipment, which makes the asset management more scientific and makes the equipment achieve the optimal cost in full life cycle ( $\mathrm{Li}$ et al., 2018; Orfanos et al., 2019). At present, the management mechanism of power grid companies has been difficult to meet the needs of the rapid development of power grid. It is urgent to transform and improve the asset management model, promote the information and digitization of asset management, and accelerate the construction of world-class power grid. Therefore, the research significance of asset life cycle management is as follows:

Firstly, it should not only implement the national strategy and enterprise strategy and continuously improve the sustainable development ability of power grid, but also vigorously promote the high-quality development of power grid and build a world-class energy internet enterprise. The concept of asset management is the source of exerting asset management efficiency and improving asset management capabilities. It plays an important role in improving the overall asset management performance of the enterprise. Enterprises must introduce advanced asset life cycle management concepts.

Secondly, enterprise asset life cycle management is not only a process of concept innovation, but also a process of technology application. By employing asset life cycle management technology, the asset life cycle resource value and asset utilization efficiency of power grid enterprises can be improved.

Thirdly, asset life cycle management concept determines the direction and content of asset management decision-making of power Grid Company, which has macro guiding significance.

Fourthly, the large scale, wide distribution and variety of assets of power grid companies increase the difficulty of life cycle management of assets of power grid companies. Power grid companies must innovate the concept of asset management, apply the full life cycle theory to asset management, take the full cost management of assets within the full life cycle as the basis for management decisions, and pay attention to the long-term nature and efficiency of asset management, which is an innovation of the traditional asset management concept (Liu et al., 2012).

\section{LCC COST ESTIMATION MODEL}

Since the concept of LCC is applied soon, there is no correlation between the historical data of relevant asset management systems of all enterprises, and the data of full life cycle is missing. Besides, the cost of equipment assets operation and maintenance can only be counted according to the management units, and cannot be collected into the equipment and the current situation of basic data cannot meet the requirements of efficient asset management (Xu and Wang, 2011). Therefore, it is necessary to estimate the assets of power system, and then estimate LCC (Liu et al., 2012;
Lee et al., 2020). LCC estimation also estimates the possible LCC in the future, which is related to the establishment of budget (Savoretti et al., 2017), quotation generation (Govil, 1984) and development strategy (Govil, 1985), which is an indispensable part of the cost efficiency (reliability) evolution model in engineering (Yang et al., 2017).

The LCC estimation method is mainly established and implemented around the cost structure of the research target equipment. A reasonable estimate of the cost of the entire life cycle of the equipment is made in the form of engineering standards, and a targeted estimation method is used in conjunction with the composition of the entire life cycle of the equipment. Through the integration of various methods and cost components, a unified and comprehensive LCC estimation model is formed. In the process of establishing and revising the estimation model, the cost calculation of a single device is realized through accounting, statistics, and apportionment of various costs based on the current data situation. Taking into account the importance and value of the equipment, the LCC estimation work uses the method of setting the correction coefficient matrix to characterize the equipment difference, and the LCC estimation model is constantly revised and improved in the long-term work by mathematical checking and empirical judgment.

\section{Structure Composition of LCC}

Based on the full life cycle management requirements and operational characteristics of the research equipment, the cost structure of each part of the equipment LCC is decomposed. In terms of selecting equipment to be studied, this article takes important equipment such as transformers, generators, and circuit breakers in the power supply equipment of the power system as the main research objects. The above important equipment occupies an important position in the operation of the power grid and has a relatively comprehensive and highly targeted Cost management process. According to the equipment survey results, combined with the current status of equipment cost management in the power grid and advanced LCC theory, the cost structure based on the LCC management method mainly includes investment costs, operating costs, maintenance costs, failure costs, scrap costs, etc. Decompose the cost of each part of LCC, and its cost structure is shown in Figure 3.

Particularly, relevant cost breakdown of LCC can be computed by:

$$
L C C=C I+C O+C M+C F+C D
$$

where $C I$ represents cost of investment; $C O$ means operating cost; $C M$ denotes maintenance cost; $C F$ stands for fault cost; $C D$ is abandon cost.

These costs can also be further broken down into sub costs, as mentioned above, LCC is related to future costs, and when the time value of funds is considered (Bastian, 2011), the cost incurred in the future shall be reduced and corrected multiply by $\left(\frac{1+r}{1+K_{c p i}}\right)^{\text {year }_{i}}$, where $K_{c p i}$ represents CPI index, which reflects inflation; $r$ denotes discount rate, and year ${ }_{i}$ means service years. 


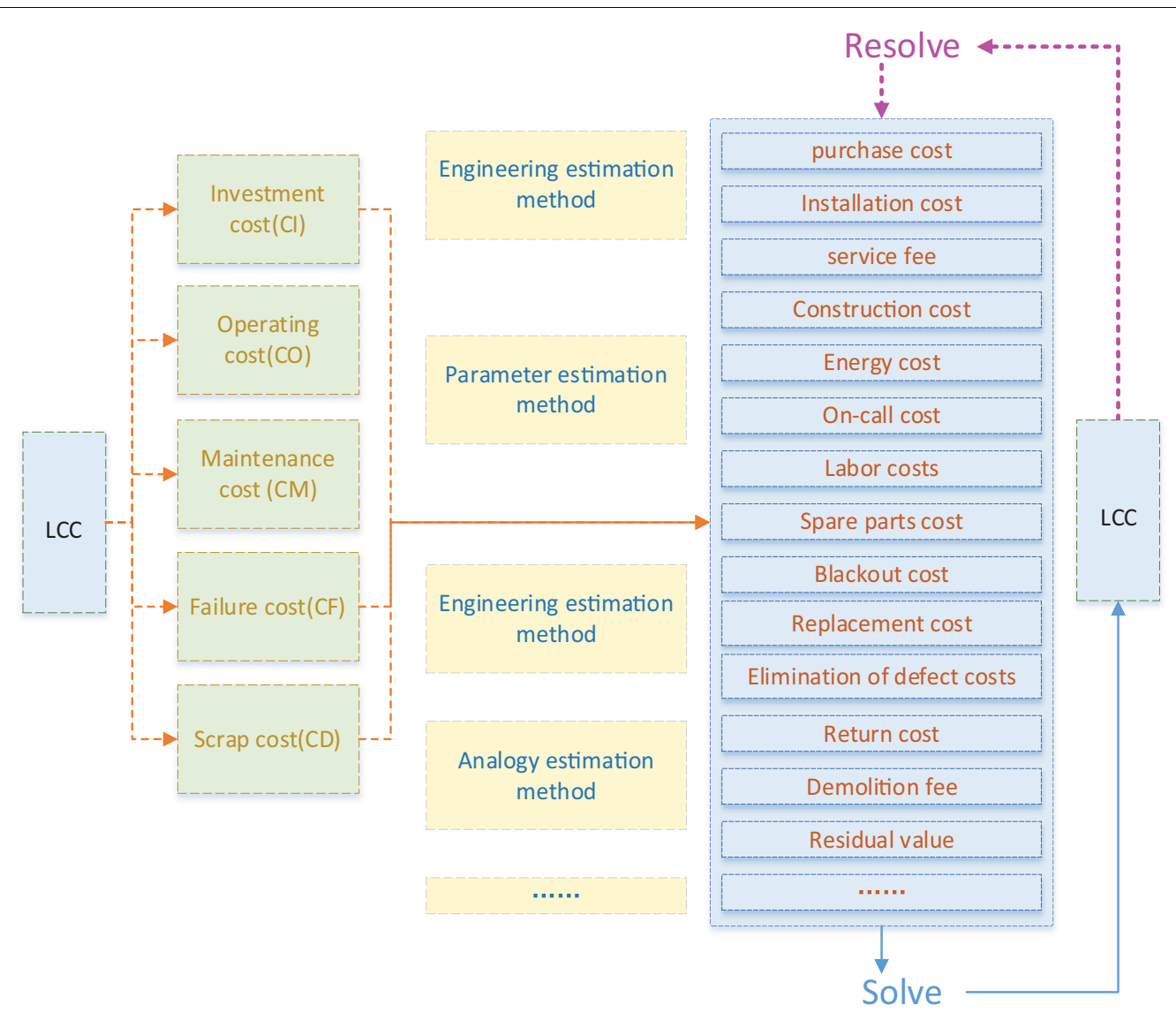

FIGURE 3 | Cost breakdown structure.

Some studies also put forward the environmental cost (Li et al., 2018), but for power supply of peak-load and frequency, it is relatively clean, so this item cannot be considered.

\section{Estimation Method}

The research object of LCC estimation is capital invested in the future (Lee et al., 2020). Through estimation of capital to be invested, it provides an important basis for economic judgment and final decision-making of the scheme (de Jong and Declercq, 2012). LCC estimation is the key content of LCC technology research and the basis of technology application.

Some studies believe that there are two main channels for data collection: professional manufacturers and suppliers, and historical data (Schneiderova-Heralova, 2018). The amount of data and information obtained determines the cost estimation method used. Besides, there are two kinds of estimation methods: certainty and uncertainty. For the former, there are more evaluation models (Cole and Sterner, 2000; Vahdat-Aboueshagh et al., 2014); for the latter, there are Monte Carlo method (Ammar et al., 2013; Goh and Sun, 2016), fuzzy set method (Shahata and Zayed, 2013; Plebankiewicz et al., 2020) and neural network (NN) (Ilg et al., 2017). For the existing asset estimation methods, the accuracy of LCC model depends on the choice of calculation method and the certainty of data. LCC of power system in estimation scheme at present is very diverse. In view of the different stages of development and enterprise data types can be estimated according to the advantages and disadvantages of the scheme selection. Defects of technological level is that the barriers to a large amount of data is temporarily unable to break in the process of cost separating, and partly by artificial decomposition cost reimbursement need to upload the data to the cloud, the time cost and the statistical labor costs rose, as a result, the unity of the intelligent data analysis big data platform construction is the core content of LCC technology, in combination with the discussion of data and analysis the process needed a big enterprise data platform construction. Therefore, the content of data application construction is not discussed. This paper only discusses the system framework and model application established by LCC asset management. The estimation methods applied in the big data analysis platform are introduced as follows:

\section{Gray Fuzzy Estimation Method}

Gray fuzzy estimation method (Chen and Ren, 2018) is that when some evaluation indexes cannot be accurately quantified, interval fuzzy method is usually used to evaluate the risk of contractor selection and installation construction unit selection. Fuzzy algorithm combines expert evaluation, fuzzy interval setting and other methods to integrate and calculate the evaluation opinions 
given by multiple experts by the evaluation registration (Miah et al., 2017), so as to obtain the comprehensive evaluation of the risk of contractor or supplier selection, and formulate the cost quantification strategy based on the risk level.

\section{Parameter Estimation Method}

Parameter estimation, which is based on a lot of historical cost data of similar equipment, selection of sensitive to cost several main physical parameters and performance features, then employing the regression analysis, gray system and neural network data processing method to set up the mathematical relationship of cost between the parameters, so as to estimate LCC or estimate the cost of a main unit. The first task of establishing the cost parameter relationship is to determine which characteristic quantity the cost is related to. In this method, the most important link is the database (Wang et al., 2013). Database must meet some specific requirements, such as establishing related connections for similar power equipment, in which each similar data unit should be composed of similar components and be processed consistently in the same way, that is, to ensure comparability. Otherwise, it will lead to obvious deviations in the estimation relationship, or even unreliable.

With the continuous accumulation of data, the model can be modified, and the more the model is used, the higher the accuracy will be. Therefore, this method is most widely used in LCC estimation, in which full LCC can be approximately related to quality, yield, performance and other characteristic variables. Compared with analogy estimation method, parameter estimation method reflects the relationship between cost and attribute. Therefore, as long as get the value of some of attribute parameters of complex system, it only needs to input the characteristic quantity to calculate the cost of the equipment at this stage. Then according to equipment reliability, maintainability and other parameters calculate the cost of operation, maintenance and scrap recovery phase, so as to obtain LCC. This method is the most commonly used cost estimation method in the early stage of full LCC analysis, especially in the absence of detailed planning and design specifications. Another advantage of establishing this kind of cost parameter relation is that it can quickly estimate the influence of the change of power equipment performance or some characteristic parameters on cost, so as to evaluate the influence of cost when the scheme is chosen during the planning and design and when the scheme is changed.

The calculation equation of parameter estimation method can be expressed as follows:

$$
C_{2}=C_{1}\left(\frac{S_{2}}{S_{1}}\right)^{n} C_{F}
$$

where $C_{1}$ represents actual engineering costs of similar projects; $C_{2}$ denotes costs required for the proposed project; $S_{1}$ means production scale of similar projects; $S_{2}$ stands for production scale of the proposed project; $C_{F}$ represents price conversion index; and $n$ denotes production scale index.

The value of $n$ : the scale is enlarged, mainly with the increase of equipment capacity, $n$ is $0.8 \sim 0.9$; for high-pressure equipment, $n$ is $0.3 \sim 0.5$, and usually the average value of $n$ is about 0.6. Therefore, this estimation method is also called 0.6 index method. However, there are obvious drawbacks to this approach. First of all, it needs a lot of historical data, which is almost impossible to obtain detailed historical data since the LCC management of power companies started late. Secondly, the model established by this method only represents the law of changes in the past costs. The period of power system engineering is large, and the geographical gap between regions is also large. These differences will lead to an increase in the error of estimation model and affect decision-making. Furthermore, comparing the various attribute parameters of a complex system, parameter estimation model only relies on limited and easily measurable parameters for cost estimation, and does not consider various situations in detail. It is generally used in the early development stage of complex system, when there are only system specifications but no detailed planning and design specifications, especially when the power equipment is not standardized. The reasonable degree of the model established by the parameter estimation method depends on the staff's understanding of the system and their modeling experience and skills. The prediction accuracy is highly subjective, and this method is no longer applicable when the new system adopts advanced development and production technology.

\section{Engineering Estimation Method}

Engineering estimation method is a traditional cost estimation method, also known as detailed estimation method or bottomup method. It uses work breakdown structure to calculate each cost unit item by item from bottom to top, and then add item by item to get the total LCC (Ilg et al., 2017). Besides, engineering estimation method divides the research object into different subparts, and carries on the cost estimation, respectively, according to different characteristics of the parameters of each part. Finally, the estimated value of each part is summed up to obtain the total LCC. This estimation method is generally used in planning, development and production of research objects. With the accumulation of analysis, more and more data support for estimation, and the result of estimation becomes more and more accurate. It starts from the lowest level work unit, calculates LCC item by item from bottom to top by using work breakdown structure, sums up the cost of each work unit in the system, and then obtains the value of the upper-level cost unit item by item, and finally obtains LCC.

When applying engineering estimation method to calculate cost of each unit, it is necessary to collect detailed data information about the relevant costs. It is not difficult to observe that the advantages of this method are detailed and specific, with high estimation accuracy, but the disadvantages are cumbersome, time-consuming, heavy workload and complex calculation process. Therefore, this method can only be adopted after detailed design and mastering the relevant information of the equipment and the cost of its use and maintenance, which can be used to estimate the cost of some decision-making problems in the later stage.

Its mathematical model can be expressed as:

$$
C=C_{1}+C_{2}+\cdots+C_{n}
$$


where $C$ represents LCC; and $C_{i}$ denote cost of each unit at different stages.

The cost of each unit can be further divided into sub-units to form a complete cost breakdown structure diagram of the equipment, so as to obtain the estimated value of the total cost. This method is a detailed estimation method, its accuracy is directly related to the amount of information obtained, and is generally used in the later stage of the project.

\section{Analogy Estimation Method}

Analogy estimation method is a method to estimate LCC of equipment by referring to the known cost information and other data of similar equipment. Based on the existing data of similar equipment, the equipment to be built is compared with it, and the fixed coefficient value is taken according to the characteristics of the latter to estimate its cost. Analogical estimation method is generally used in the early stage of equipment life, and its accuracy depends on expert experience.

When the data of similar power equipment is relatively reliable and the database is complete, this method is a more suitable estimation method. In most cases, it is used in the early planning and design stage of LCC to preliminarily estimate full LCC of power equipment.

It is a method to estimate the cost of the target equipment by comparing known information of the same type of equipment. Particularly, the implementation steps are as follows: firstly, select the sampling equipment, and the key parameters of the sampling equipment shall be the same as the existing equipment, and then compare the existing equipment with the sampling equipment. During the comparison, the characteristic parameters of the existing equipment can be set according to the different points between the equipment. Finally, LCC is obtained through comparing the characteristic parameters with the historical values of the sampling equipment. As the key part of the analogy method, the characteristic parameters in the actual use, usually call some experts, comprehensive research and judgment after the value, so the analogy method is also known as the expert method. This method is mainly employed in the planning and feasibility study stage at the initial stage of engineering construction, which applies to the situation that the data of similar projects are more accurate and detailed.

Moreover, it is a method to estimate LCC by referring to the cost data of completed projects similar to construction projects (Angelis and Stamelos, 2000; Steinert, 2009). Employing the analogy method to calculate the cost is mainly to use the cost data of similar projects, and select the correlation coefficient to correct according to the specific situation, so as to accurately estimate the cost of the proposed project. The selection of correlation coefficient is very important, which is generally determined by consulting experts. Its mathematical model can be expressed as:

$$
C=C_{0} \sum_{i=1}^{n} a_{i} K_{i}
$$

where $C$ denotes cost of proposed project; $C_{0}$ represents cost of similar projects; $a_{i}$ stands for the proportion of labor cost, material cost and procurement cost in the total cost of similar projects; $K_{i}$ means the correlation coefficient of labor cost, material cost and purchase cost between the proposed project and similar project.

The analogy method estimates the cost based on the cost of similar products or technologies in the past. Besides, this method updates the historical data to reflect the impact of rising costs and technological progress, which is suitable for cost estimation with historical data and actual data reference.

\section{Neural Network Method}

Artificial neural network (ANN) has been studied since the early 1940 s, which is an intelligent computing system that simulates a biological NN with a computer network system. Furthermore, ANN can simulate some unique behaviors of the human brain, such as learning, memory, and recall, through self-learning, selforganization, self-adaptation, and nonlinear dynamic processing. The main advantages of NN estimation method are as follows: because ANN owns self-learning function, through the network data training, it can quickly and accurately simulate the results, so it does not need to establish a specific mathematical model of the cost. There are many uncertain factors, such as different electrical parameters, equipment operating conditions, climate, policies, etc., in LCC estimation of power transformers, so it is more accurate and objective to use neural network to calculate.

However, NN estimation method also has certain shortcomings: a large amount of historical data of power transformers is required during model training, and this data is often lacking in practical applications; the choice of hidden layers does not have a very scientific basis, which can be determined after trial calculation; it is not easy to obtain the sensitivity of the key factors of LCC of power transformers.

\section{Activity-Based Costing Method}

Activity-based costing (ABC) is employed to calculate the cost of the equipment by summing up the activities related to the power equipment (Özbayrak et al., 2004; Karim et al., 2012). Based on historical information or estimated data, it first calculates the unit cost of each activity, and then calculates the activity consumed by new equipment, multiplying the two to get the total cost of power equipment (Waghmode and Sahasrabudhe, 2012; Bierer et al., 2015). It is mainly used in the later stage of LCC. The practical operation steps are as follows: (1) select the main activity; (2) collect the cost of resources to the homogeneous cost base; (3) select the cost driver; (4) calculate the allocation rate of each cost base; (5) allocate the collected cost in each cost base to power equipment according to allocation rate of cost base; (6) summarize and calculate the total cost of power equipment. The main problem of this method is that it is not easy to obtain unit activity cost (Ben-Arieh and Qian, 2003).

\section{Case-Based Reasoning Method}

In short, case-based reasoning method (CBR) adopts past problem-solving methods to deal with new problems (Ji et al., 2012). Its main spirit lies in how to systematically preserve and deal with the previous problem-solving knowledge and experience, in order to solve the new or repeated problems encountered, so as to reduce the mass of information, avoid 
repeated process load. At the same time, CBR can accumulate experience. Each time a problem is solved, the new experience is saved. Nearest neighbor technique is probably the most widely used technique in CBR. For each case attribute, determine the similarity between the problem (target) case and the cases in the case base. This measure can be multiplied by a weighting factor. The similarity sum of all attributes is then calculated to provide a similarity measure between the case in the library and the target case.

The estimation range of LCC in CBR is limited by sample value and cannot be extrapolated, but its characteristic parameter quantity is independent of sample size. That is, the number of feature attributes can be increased a lot. Besides, it doesn't need to judge the number of feature coefficients by considering the number of samples. Moreover, CBR method is simple and can obtain superior estimation results.

\section{Expert Estimation Method}

Expert estimation method is the estimated value of full LCC of equipment based on expert experience judgment, which is the application of Delphi method in the prediction technology in cost estimation (Steinert, 2009). When using the expert estimation method, a certain number of experts independently estimate the corresponding equipment, and then synthesize them to obtain the estimated cost of equipment. Particularly, expert estimation method is generally adopted in the absence of data or the difficulty of collection, and the insufficient number of statistical samples, as well as employed as an auxiliary estimation of other estimation methods. Its mathematical model can be expressed as follows:

$$
C=\frac{\sum_{i=1}^{n} C_{i}}{n}
$$

where $C$ denotes the estimated value of cost unit, here the average value is taken; $C_{i}$ is the estimated value of the $i$ th expert for cost unit; and $n$ is the number of experts participating in the estimation.

\section{Blind Number Theory Estimation Method}

Blind number theory estimation method is to comprehensively consider the attributes and characteristics of various uncertain information from the initial purchase to the later decommissioning process, and make a reasonable evaluation of the uncertain information, so as to determine the blind number expression of full LCC (Liming and Bo, 2020).

Blind number expressions are expressed by the following equation:

$$
f(x)=\left\{\begin{array}{c}
a_{k}, x=x_{k}(k=1,2, \cdots, n) \\
0, \text { otherwise }
\end{array}\right.
$$

where $a_{k}$ indicates the reliability of a blind number; $x=x_{k}$ represents a possible value or range of possible values for a blind number.

Compared with traditional deterministic LCC calculation method, LCC method based on blind number theory can't only calculate the expected value of LCC, but also obtain possible distribution intervals of different costs and corresponding credibility information, so as to improve the rationality of estimation results.

\section{Comparison of Various Estimation Methods}

The purpose and precision of LCC estimation vary greatly in different stages due to variety and complexity of power equipment. Therefore, LCC estimation methods and models are not invariable, and different estimation algorithms are needed according to characteristics of collected historical data. Particularly, it concluded characteristics of different estimation methods, as shown in Table $\mathbf{1 .}$

The focus of this part is to analyze and evaluate the most suitable and accurate LCC evaluation method according to different equipment categories, different equipment life stages and different data conditions.

In big data era, LCC estimated model at technical level can be combined with the deep learning framework to forecast, should not satisfy with the traditional estimation method, cyber-physical system and knowledge graph is the future of artificial intelligence in an important direction in big data analysis scenarios, the LCC estimation in the new method of artificial intelligence can be used on innovation breakthrough.

\section{LCC Estimation Model of Power Assets}

According to cost estimation model of different life cycle stages of power assets, LCC of power assets is estimated. The following is the detailed scheme of LCC cost structure separation to point out the data path and separation ideas, and the LCC cost reduction formula for a supplementary explanation. The cost mapping relationship of each cycle in cost collection and estimation is explained. As for the content of mutual diffraction in the cost of each life cycle, it is a reasonable method to establish the standard of cost calculation system within the stage to solve the superposition effect of cost. The content of LCC cost estimation standard is introduced as follows.

\section{Investment Costs}

The cost of investment and construction from start of planned construction to formal operation (excluding subsequent technical reform) mainly includes:

$$
C I=C_{\text {purchase }}+C_{\text {installation }}+C_{\text {construction }}+C_{\text {field service }}
$$

where $C_{\text {purchase }}$ denotes purchase cost; $C_{\text {installation }}$ represents installation cost; $C_{\text {construction }}$ means construction cost; and $C_{\text {field service }}$ stands for field service cost.

\section{Operating Costs}

Operating costs can be expressed as follows:

$$
C O=C_{\text {energy }}+C_{\text {duty }}
$$

where $C_{\text {energy }}$ represents energy cost; and $C_{\text {duty }}$ denotes onduty cost. 
TABLE 1 | Summary of characteristics of different estimation methods.

\begin{tabular}{|c|c|c|c|c|}
\hline Methods & Uncertainty & Application phase & Accuracy & Historical data \\
\hline Parametric estimation method & Medium & Early stage & Medium & Many \\
\hline Engineering estimation method & Low & Mid-late stage & High & Many \\
\hline Analogy estimation method & High & Early stage & Low & Average \\
\hline Neural Network method & medium & early stage & high & many \\
\hline Expert estimation method & High & Early stage & Low & Few \\
\hline Blind number theory estimation method & Medium & Early stage & Low & Fewer \\
\hline
\end{tabular}

\section{Maintenance Costs}

Maintenance costs can be computed by:

$$
C M=C_{\text {labor }(\mathrm{CM})}+C_{\text {supply }(\mathrm{CM})}+C_{\text {spare }(\mathrm{CM})}
$$

where $C_{\text {labor }}$ represents labor costs; and $C_{\text {supply }}$ denotes supply cost; and $C_{\text {spare }}$ means spare cost.

\section{Fault Costs}

Fault costs can be expressed by:

$$
C F=C_{\text {blackout }}+C_{\text {replace }}+C_{\text {deficiency }}+C_{\text {withdrawal }}
$$

where $C_{\text {blackout }}$ means power blackout cost; $C_{\text {replace }}$ denotes equipment replace cost; $C_{\text {deficiency }}$ represents deficiency cost; and $C_{\text {withdrawal }}$ means withdrawal cost.

\section{Discard Costs}

Discard costs can be computed by:

$$
C D=C_{\text {scrap }}+C_{\text {residual value }}
$$

where $C_{\text {scrap }}$ means scrap cost; and $C_{\text {residual value }}$ denotes residual value.

Recoverable costs can be estimated by parameter estimation: residual value is approximately equivalent to the product of the weight of steel and its price, or the original value of the equipment is added with a proportional coefficient.

Asset management system of project cost detail work, there are detailed classification is too rough form, it fails to meet the project cost to carry out the elaboration to the equipment and component levels of business requirements, therefore the present solutions for the project was obtained from the financial management system of financial course code and cost detail, after the model to further improve the account of the project cost, for the enterprise of the management system of data interface, after the export project cost detail, project data cleansing, obtain the LCC cost collects the required at all levels in different stages of the data.

\section{Reliability Evaluation of LCC Estimation Method}

In the construction of the theoretical model, must be based on historical data, using the total life cycle cost calculation model, calculation and analysis on specific historical node balance data, and combining with the investment cost is the subsequent comprehensive analysis comparison, the calculation model of correction methods, to ensure the effectiveness and reliability of the final model in the actual production. That is, with the application of the system, the model algorithm can be modified in real time by comparing the difference between the actual cost accounting and the data platform estimation model.

The model constructed by historical data predicts the situation of the plant or similar projects in the same area in the same period, and compares the actual data to verify whether the error between the calculation results of the model and the actual results is within a certain allowable range. If so, the model is accurate. On the contrary, it is necessary to consider revising or even changing the model, and study two ways of revising the model based on the revision method of years and the revision method based on economic parameters.

The cost structure split based on the whole life cycle management method basically includes the economic investment generated in equipment management. The LCC management method implemented around the cost structure needs to be adjusted in conjunction with the data foundation and the characteristics of the equipment object, and the cost structure is increased or decreased and optimized when necessary to ensure that the economic indicators of the equipment are comprehensively and systematically considered in the implementation of the LCC management.

\section{CONCLUSION}

Combined with LCC analysis of power assets, full LCC management method is adopted for peak-load and frequency regulation enterprises, which can't only be adopted for project cost budget, but also better guide a safe production and reliable operation, such as procurement, maintenance and scrap planning, as well as risk control.

In the application of full life cycle management, necessary data and information should be obtained to decompose each stage according to different costs, calculate appropriate estimation model, and collect from upper-level step by step to estimate final full LCC. Considering the time value of the capital, future-oriented full LCC needs to be converted into currentoriented value to facilitate the comparison and analysis of different schemes.

Since the transparency of data and information in different stages of full life cycle is different, various estimation algorithms should be carefully selected according to the characteristics of each period. At the same time, there are errors in estimation, 
so the value of such uncertainty needs to be recognized. In the research, it is necessary to focus on the important systems and equipment, take the $20-80$ principle as the analysis standard, and reasonably consider the research scope and precision of the equipment cost. The equipment content of asset management should be classified as primary and secondary in the classification of the equipment tree, and the importance level of the equipment should be divided. The equipment content with higher importance should focus on the evolution process of cost efficiency of LCC. The overall goal of power equipment cost model estimation is to have the lowest LCC of power equipment in the whole life cycle, and the goal of each stage is to have the lowest cost of each stage under the condition of meeting the total goal. Therefore, the target value of the consumption cost of each stage can be established to provide reference for the management mode of each stage of power equipment.

To sum up, the implementation of LCC needs to establish a complete database, a scientific decomposition mechanism, an appropriate estimation model and cooperation between various departments, which aims to improve accuracy of full LCC estimation and guide a satisfactory management of assets with a high assets efficiency.

\section{REFERENCES}

Ammar, M., Zayed, T., and Moselhi, O. (2013). Fuzzy-based life-cycle cost model for decision making under subjectivity. J. Constr. Eng. Manag. 139, 556-563. doi: $10.1061 /$ (asce)co.1943-7862.0000576

Angelis, L., and Stamelos, I. (2000). A simulation tool for efficient analogy based cost estimation. Empir. Softw. Eng. 5, 35-68.

Arif, M., and Khan, M. E. (2010). Design and life cycle cost analysis of a SAPV system to electrify a rural area household in India. Curr. World Environ. 5, 101-106. doi: 10.12944/cwe.5.1.15

Asiedu, Y., and Gu, P. (1998). Product life cycle cost analysis: state of the art review. Int. J. Prod. Res. 36, 883-908. doi: 10.1080/002075498193444

Bajaj, A., Kekre, S., and Srinivasan, K. (2004). Cost and schedule performance in design and manufacturing management science. Manag. Sci. 50, 527-536. doi: $10.1287 / \mathrm{mnsc} .1030 .0177$

Basmadjian, R., and Meer, H. (2018). A heuristics-based policy to reduce the curtailment of solar-power generation empowered by energy-storage systems. Electronics 7, 349-370. doi: 10.3390/electronics7120349

Bastian, N. D. (2011). Optimizing army sustainability at fort bragg: a case study connecting life-cycle cost analysis with leadership in energy and environmental design for existing buildings. Eng. Manag. J. 23, 42-54. doi: 10.1080/10429247. 2011.11431894

Ben-Arieh, D., and Qian, L. (2003). Activity-based cost management for design and development stage. Int. J. Prod. Econ. 83, 169-183. doi: 10.1016/s0925-5273(02) 00323-7

Bierer, A., Götze, U., Meynerts, L., and Sygulla, R. (2015). Integrating life cycle costing and life cycle assessment using extended material flow cost accounting. J. Clean. Prod. 108, 1289-1301. doi: 10.1016/j.jclepro.2014. 08.036

Billinton, R., and Huang, D. (2010). Wind power modelling and the determination of capacity credit in an electric power system. Proc. Inst. Mech. Eng. 224, 1-9. doi: 10.1243/1748006xjrr266

Bird, L., Lew, D., Milligan, M., Carlini, E. M., Estanqueiro, A., and Flynn, D. (2016). Wind and solar energy curtailment: a review of international experience. Renew. Sustain. Energy Rev. 65, 577-586.

Cai, Y. Z., Liu, L., Cheng, H. Z., Ma, Z. L., and Zhu, Z. L. (2011). Application review of life cycle cost (LCC) technology in power system. Power Syst. Protect. Control 39, 149-154.
Therefore, future research will focus more on improving the asset management level and the accuracy of the estimation model, and on this basis, consider a better combination of cost and efficiency. This is the next direction of work.

\section{AUTHOR CONTRIBUTIONS}

KW contributed to conceptualization. YL contributed to data curation and writing. XW contributed to formal analysis. NY contributed to funding acquisition. SY contributed to methodology. ZZ contributed to project administration. YW and TY contributed to resources. ZH contributed to visualization. All authors contributed to the article and approved the submitted version.

\section{ACKNOWLEDGMENTS}

The authors gratefully acknowledge the support of the analysis and research of power generation equipment management decision model based on LCC (STKJXM20190123).

Chen, H., Cong, T. N., Yang, Y., Tan, C., Li, Y., and Ding, Y. (2009). Progress in electrical energy storage system: a critical review. Prog. Nat. Sci. 19, 291-312. doi: 10.1016/j.pnsc.2008.07.014

Chen, L., and Ren, J. (2018). Multi-attribute sustainability evaluation of alternative aviation fuels based on fuzzy ANP and fuzzy grey relational analysis. J. Air Trans. Manag. 68, 176-186. doi: 10.1016/j.jairtraman.2017.10.005

Cole, R. J., and Sterner, E. (2000). Reconciling theory and practice of life-cycle costing. Build. Res. Inform. 28, 368-375. doi: 10.1080/096132100418519

Curry, E. E. (1989). STEP: a tool for estimating avionics life cycle costs. Aerosp. Electron. Syst. Magazine IEEE. 4, 30-32. doi: 10.1109/62.16986

Danish, M. S. S., Yona, A., and Senjyu, T. (2014). Pre-design and life cycle cost analysis of a hybrid power system for rural and remote communities in Afghanistan. J. Eng. 2014, 438-444. doi: 10.1049/joe.2014.0172

de Jong, M., and Declercq, K. (2012). Economic evaluation of urban track systems: integration of life cycle costs and socio-economic assessment. Proc. Soc. Behav. Sci. 48, 1264-1273. doi: 10.1016/j.sbspro.2012.06.1102

Dui, X., Zhu, G., and Yao, L. (2018). Two-stage optimization of battery energy storage capacity to decrease wind power curtailment in grid-connected wind farms. IEEE Trans.Power Syst. 33, 3296-3305. doi: 10.1109/tpwrs.2017.2779134

Feng, Y., Lin, H., Ho, S. L., Yanc, J., Dong, J., and Fang, S. (2015). Overview of wind power generation in China: status and development. Renew. Sustain. Energy Rev. 50, 847-858.

Furch, J. (2016). A model for predicting motor vehicle life cycle cost and its verification. Trans. FAMENA. 40, 15-26.

Goh, B. H., and Sun, Y. (2016). The development of life-cycle costing for buildings. Build. Res. Inform. 44, 319-333.

Govil, K. K. (1984). New analytical models for logistics support cost and life cycle cost vs reliability function. Microelectron. Reliabil. 24, 61-63. doi: 10.1016/ 0026-2714(84)90638-3

Govil, K. K. (1985). Optimum design of reliable systems for specified life cycle cost. Microelectron. Reliabil. 25, 239-241. doi: 10.1016/0026-2714(85)90007-1

Hedley-Whyte, J. (2000). Standardization of interface design for medical devices: international electrotechnical commission and international organization for standardization medical alarm systems. Hum. Fact. Ergon. Soc. Annu. Meeting Proc. 44, 215-218. doi: 10.1177/154193120004400158

Hu, Y., and Cheng, H. (2013). Development and bottlenecks of renewable electricity generation in China: a critical review. Environ. Sci. Technol. 47, 3044-3056. doi: 10.1021/es303146q 
Ilg, P., Scope, C., Muench, S., and Guenther, E. (2017). Uncertainty in life cycle costing for long-range infrastructure. Part I: leveling the playing field to address uncertainties. Int. J. Life Cycle Assess. 22, 277-292. doi: 10.1007/s11367-0161154-1

Ji, S. H., Park, M., and Lee, H. S. (2012). Case adaptation method of case-based reasoning for construction cost estimation in Korea. J. Construct. Eng. Manag. 138, 43-52. doi: 10.1061/(asce)co.1943-7862.0000409

John, E. (2017). Economic and technical challenges of flexible operations under large-scale variable renewable deployment. Energy Econ. 64, 363-372. doi: 10.1016/j.eneco.2017.04.012

Joseph, T., Ugalde-Loo, C. E., Liang, J., and Coventry, P. F. (2018). Asset management strategies for power electronic converters in transmission networks: application to HVDC and FACTS devices. IEEE Access. 6, 2108421102. doi: 10.1109 /access.2018.2826360

Karamouz, M., Yaseri, K., and Nazif, S. (2017). Reliability-based assessment of lifecycle cost of urban water distribution infrastructures. J. Infrastruct. Syst. 23:04016030. doi: 10.1061/(asce)is.1943-555x.0000324

Karim, H., Magnusson, R., and Natanaelsson, K. (2012). Life-cycle cost analyses for road barriers. J. Trans. Eng. 138, 830-851. doi: 10.1061/(asce)te.1943-5436. 0000391

Kasis, A., Devane, E., Spanias, C., and Lestas, I. (2016). Primary frequency regulation with load-side participation part I: stability and optimality. IEEE Trans. Power Syst. 32, 3505-3518. doi: 10.1109/tpwrs.2016.2636286

Kim, G. T., Kim, K. T., Lee, D. H., Han, C. H., Kim, H. B., and Jun, J. T. (2010). Development of a life cycle cost estimate system for structures of light rail transit infrastructure. Autom. Construct. 19, 308-325. doi: 10.1016/j.autcon.2009.12. 001

Kiritsis, D., Neuendorf, K. P., and Xirouchakis, P. (1999). Petri net techniques for process planning cost estimation. Adv. Eng. Softw. 30, 375-387. doi: 10.1016/ s0965-9978(98)00126-4

Lee, J., Yang, H., Lim, J., Hong, T., Kim, J., and Jeong, K. (2020). BIM-based preliminary estimation method considering the life cycle cost for decisionmaking in the early design phase. J. Asian Arch. Build. Eng. 19, 384-399. doi: $10.1080 / 13467581.2020 .1748635$

Lee, S. Y., Jo, C., Bergan, P., Pettersen, B., and Chang, D. (2016). Life-cycle costbased design procedure to determine the optimal environmental design load and target reliability in offshore installations. Struct. Saf. 59, 96-107. doi: 10.1016/j.strusafe.2015.12.002

Li, X., Chalvatzis, K. J., and Stephanides, P. (2018). Innovative energy islands: life-cycle cost-benefit analysis for battery energy storage. Sustainability 10, $1-19$.

Liming, S., and Bo, Y. (2020). Nonlinear robust fractional-order control of battery/SMES hybrid energy storage systems. Power Syst. Protect. Control 48, 76-83.

Liu, H., Gopalkrishnan, V., Quynh, K. T. N., and Ng, W. (2008). Regression models for estimating product life cycle cost. J. Intell. Manuf. 20, 401-408. doi: 10.1007/s10845-008-0114-4

Liu, L., Wang, H., Cheng, H., and Liu, J. (2012). Economic evaluation of power systems based on life cycle cost. Autom. Electr. Power Syst. 36, 45-50. doi: 10.4324/9781315611730-12

Lombardi, L. (2003). Life cycle assessment comparison of technical solutions for $\mathrm{CO} 2$ emissions reduction in power generation. Energy Convers. Manag. 44, 93-108. doi: 10.1016/s0196-8904(02)00049-3

Luo, X., Li, L., and Wei, Z. (2011). Applications of life cycle cost theory in decisionmaking of investment for distribution transformers renovation. Power Syst. Technol. 35, 207-211.

Mascitelli, R. (2004). A simple cost evcluator for product design. Mach. Des. 76, 98-102.

Meyer, C., and De Doncker, R. W. (2006). LCC analysis of different resonant circuits and solid-state circuit breakers for medium-voltage grids. IEEE Trans. Power Deliv. 21, 1414-1420. doi: 10.1109/tpwrd.2005.861334

Miah, J. H., Koh, S. C. L., and Stone, D. (2017). A hybridised framework combining integrated methods for environmental life cycle assessment and life cycle costing. J. Clean. Produ. 168, 846-866. doi: 10.1016/j.jclepro.2017.08.187

Nilsson, J., and Bertling, L. (2007). Maintenance management of wind power systems using condition monitoring systems-life cycle cost analysis for two case studies. IEEE Trans. Energy Convers. 22, 223-229. doi: 10.1109/tec.2006.8 89623
Orfanos, N., Mitzelos, D., Sagani, A., and Dedoussis, V. (2019). Lifecycle environmental performance assessment of electricity generation and transmission systems in Greece. Renew. Energy 139, 1447-1462. doi: 10.1016/j. renene.2019.03.009

Ozbay, K., Jawad, D., Parker, N., and Hussain, S. (2004). Life-cycle cost analysis: state of the practice versus state of the art. Trans. Res. Record J. Trans. Res. Board 1864, 62-70. doi: 10.3141/1864-09

Özbayrak, M., Akgün, M., and Türker, A. K. (2004). Activity-based cost estimation in a push/pull advanced manufacturing system. Int. J. Prod. Econ. 87, 49-65. doi: 10.1016/s0925-5273(03)00067-7

Park, J., and Simpson, T. W. (2003). Production cost modeling to support product family design optimization. Math. Problems Eng. 2003, 165-174.

Plebankiewicz, E., Meszek, W., Zima, K., and Wieczorek, D. (2020). Probabilistic and fuzzy approaches for estimating the life cycle costs of buildings under conditions of exposure to risk. Sustainability 12, 226-236. doi: 10.3390/ sul 12010226

Savoretti, A., Mandolini, M., Raffaeli, R., and Germani, M. (2017). Analysis of the requirements of an early life-cycle cost estimation tool: an industrial survey. Procedia Manuf. 11, 1675-1683. doi: 10.1016/j.promfg.2017.07.291

Schneiderova-Heralova, R. (2018). Importance of life cycle costing for construction projects. Eng. Rural Dev. 17, 1223-1227.

Seo, K. K., Park, J. H., Jang, D. S., and Wallace, D. (2002). Approximate estimation of the product life cycle cost using artificial neural networks in conceptual design. Int. J. Adv. Manuf. Technol. 19, 461-471. doi: 10.1007/s001700200049

Shafiee, M., Brennan, F., and Espinosa, I. A. (2016). A parametric whole life cost model for offshore wind farms. Int. J. Life Cycle Assess. 21, 961-975. doi: $10.1007 / \mathrm{s} 11367-016-1075-\mathrm{z}$

Shahata, K., and Zayed, T. (2013). Simulation-based life cycle cost modeling and maintenance plan for water mains. Struct. Infrastruct. Eng. 9, 403-415. doi: $10.1080 / 15732479.2011 .552509$

Shahidehpour, M., and Ferrero, R. (2005). Time management for assets: chronological strategies for power system asset management. IEEE Power Energy Magazine. 3, 32-38. doi: 10.1109/mpae.2005.1436498

Shi, J. N., Han, H. L., and Xu, T. (2009). Application of life cycle costs analysis in planning design of power transformation projects. Power Syst. Technol. 9, 63-66.

Solomon, R., Sandborn, P. A., and Pecht, M. G. (2000). Electronic part life cycle concepts and obsolescence forecasting. IEEE Trans. Compon. Packaging Technol. 23, 707-717. doi: 10.1109/6144.888857

Spertino, F., and Graditi, G. (2014). Power conditioning units in grid-connected photovoltaic systems: a comparison with different technologies and wide range of power ratings. Solar. Energy. 108, 219-229.

Steen, B. (2005). Environmental costs and benefits in life cycle costing. Manag. Environ. Qual. Int. J. 16, 107-118. doi: 10.1108/14777830510583128

Steinert, M. (2009). A dissensus. Technol. Forecast. Soc. Chang. 76, 291-300.

Tian, Z., Jin, T., Wu, B., and Ding, F. (2011). Condition based maintenance optimization for wind power generation systems under continuous monitoring. Renew. Energy. 36, 1502-1509. doi: 10.1016/j.renene.2010.10.028

Vahdat-Aboueshagh, H., Nazif, S., and Shahghasemi, E. (2014). Development of an algorithm for sustainability based assessment of reservoir life cycle cost using fuzzy theory. Water Resour. Manag. 28, 5389-5409. doi: 10.1007/s11269-0140808-7

Waghmode, L. Y., and Sahasrabudhe, A. D. (2012). Modelling maintenance and repair costs using stochastic point processes for life cycle costing of repairable systems. Int. J. Comput. Integr. Manuf. 25, 353-367. doi: 10.1080/0951192x. 2010.551783

Wang, H. S., Wang, Y. N., and Wang, Y. C. (2013). Cost estimation of plastic injection molding parts through integration of PSO and BP neural network. Exp. Syst. Appl. 40, 418-428. doi: 10.1016/j.eswa.2012.01.166

Wen, F., Hua, D., Wang, Q., and Singh, S. N. (2008). Wind power generation in china: present status and future prospects. Int. J. Energy Technol. Policy. 6, 736-744.

White, G. (1976). The life cycle cost of an item is the sum of all funds expended in support of the item from its conception and fabrication through its operation to the end of its useful life. Manag. Accounting 57, 39-42.

Woodward, D. G. (1997). Life cycle costing-theory, information acquisition and application. Int. J. Project Manag. 15, 335-344. doi: 10.1016/s0263-7863(96) 00089-0 
Xu, W. R., and Wang, W. M. (2011). Summary and analysis of asset life cycle cost supported by the fixed grid asset operation and maintenance cost. East China Electric Power. 39, 1588-1591.

Yang, J., Liu, Q., Li, X., and Cui, X. (2017). Overview of wind power in China: status and future. Sustainability 9, 1-12. doi: 10.1002/9781118910054.ch1

Yeung, A. A., Yoho, K. D., and Arkes, J. (2013). Estimates of unit cost reductions of the F-16 fighter as a result of U.S. arms export production. J. Cost Anal. Parametr. 6, 3-22. doi: 10.1080/1941658x.2013.766547

Yildiz, B., and Kazimi, M. S. (2006). Efficiency of hydrogen production systems using alternative nuclear energy technologies. Int. J. Hydrogen Energy. 31, 77-92. doi: 10.1016/j.ijhydene.2005.02.009

Zakeri, B., and Syri, S. (2015). Electrical energy storage systems: a comparative life cycle cost analysis. Renew. Sustain. Energy Rev. 42, 569-596. doi: 10.1016/j.rser. 2014.10.011

Zhang, G., and Wang, W. (2012). The research of comprehensive evaluation model for thermal power equipment based on life cycle cost. Syst. Eng. Procedia 4, 68-78. doi: 10.1016/j.sepro.2011.11 .051
Zhang, Y., and Cai, M. (2014). Overall life cycle comprehensive assessment of pneumatic and electric actuator. Chin. J. Mech. Eng. 27, 584-594. doi: 10.3901/ cjme.2014.03.584

Conflict of Interest: KW, YL, XW, ZZ, and YW were employed by the company CSG POWER GENERATION CO., LTD.

The remaining authors declare that the research was conducted in the absence of any commercial or financial relationships that could be construed as a potential conflict of interest.

Copyright (c) 2021 Wang, Li, Wang, Zhao, Yang, Yu, Wang, Huang and Yu. This is an open-access article distributed under the terms of the Creative Commons Attribution License (CC BY). The use, distribution or reproduction in other forums is permitted, provided the original author(s) and the copyright owner(s) are credited and that the original publication in this journal is cited, in accordance with accepted academic practice. No use, distribution or reproduction is permitted which does not comply with these terms. 